\title{
Green synthesis of gold nanoparticles using fungus Mariannaea sp. HJ and their catalysis in reduction of 4-nitrophenol
}

\author{
Xiaofang Pei ${ }^{1}$ Yuanyuan $\mathrm{Qu}^{1}$ - Wenli Shen ${ }^{1} \cdot \mathrm{Huijie} \mathrm{Li}^{2} \cdot$ Xuwang Zhang ${ }^{1}$. \\ Shuzhen $\mathrm{Li}^{1,3} \cdot$ Zhaojing Zhang ${ }^{1,3} \cdot$ Xuanying $\mathrm{Li}^{1}$
}

Received: 9 March 2017 / Accepted: 29 June 2017 / Published online: 27 July 2017

(C) Springer-Verlag GmbH Germany 2017

\begin{abstract}
In the present study, biosynthesis of gold nanoparticles (AuNPs) by the cells (cells-AuNPs) and cell-free extracts (extracts-AuNPs) of a new fungus Mariannaea sp. HJ was reported. The as-synthesized particles were characterized by UV-vis spectroscopy, transmission electron microscopy (TEM), X-ray diffraction (XRD), and Fourier transform infrared spectroscopy (FTIR). The effects of different parameters on AuNP biosynthesis were investigated, and initial gold ion concentration of $2 \mathrm{mM}, \mathrm{pH} 7$, was demonstrated to be suitable for both cells-AuNP and extracts-AuNP syntheses. The cellsAuNPs were of various shapes, including sphere, hexagon, and irregular shapes, with an average size of $37.4 \mathrm{~nm}$, while the extracts-AuNPs were almost spherical and pseudospherical with an average size of $11.7 \mathrm{~nm}$. XRD pattern suggested that the crystal structure of both AuNPs was facecentered cubic. FTIR spectra implied that some biomolecules from the fungal cell walls or cell-free extracts were involved in
\end{abstract}

Responsible editor: Santiago V. Luis

Electronic supplementary material The online version of this article (doi:10.1007/s11356-017-9684-z) contains supplementary material, which is available to authorized users.

Yuanyuan Qu

qyy@dlut.edu.cn

1 State Key Laboratory of Fine Chemicals, Key Laboratory of Industrial Ecology and Environmental Engineering (Ministry of Education), School of Environmental Science and Technology, Dalian University of Technology, Dalian 116024, China

2 Hebei Morlans Environmental Technology Co., Ltd., Shijiazhuang 050035, China

3 Key Laboratory of Environmental Biology, Research Center for Eco-Environmental Sciences, Chinese Academy of Sciences, Beijing 100085, China the formation of AuNPs. The as-synthesized AuNPs were demonstrated to have excellent catalytic activities for the reduction of 4-nitrophenol with the catalytic rate constants of $5.7 \times 10^{-3} / \mathrm{s}$ for cells-AuNPs and $24.7 \times 10^{-3} / \mathrm{s}$ for extractsAuNPs. To the best of our knowledge, this is the first report on AuNP biosynthesis by Mariannaea sp.

Keywords Gold nanoparticles · Biosynthesis · Mariannaea sp. · 4-Nitrophenol $\cdot$ Catalytic activity

\section{Introduction}

Gold nanoparticles (AuNPs) have shown remarkable potentials for numerous applications in photonics, catalysis, imaging technology, drug delivery, and space science due to their good stability, biocompatibility, and oxidation resistance which are different from bulk gold (Barabadi et al. 2017; Daniel and Astruc 2004; Schröfel et al. 2014). Various methods have been developed to produce AuNPs, among which the biological synthesis of AuNPs as an emerging highlight has attracted more and more attention due to its advantages of clean, costeffective, and environmentally friendly nature (Mandal et al. 2006; Narayanan and Sakthivel 2010; Pereira et al. 2015; Lallawmawma et al. 2015). However, accurate control of size, morphology, and monodispersity of biosynthesized nanoparticles is still one of the big challenges.

A number of microorganisms have been reported to have the capacity of reducing gold ions into AuNPs, including bacteria, fungi, yeasts, and actinomyces (Cai et al. 2011; Shedbalkar et al. 2014; Narayanan and Sakthivel 2011; Pimprikar et al. 2009; Manivasagan et al. 2015). The active molecules present in microbial 
system can be used as reducing and stabilizing agents for the biosynthesis process; thus, no other chemical reagent is required. Among the microbes, fungi are considered as superior microbial resources for the green synthesis of AuNPs due to their high production of biomass, easy handling, and high metal tolerance (Kitching et al. 2015; Das et al. 2012). Mukherjee et al. (2001) firstly reported that the eukaryotic organisms could synthesize AuNPs by the co-incubation of fungus Verticillium sp. and $\mathrm{HAuCl}_{4}$. Since then, several fungal species have been demonstrated to successfully synthesize AuNPs through intra- or extracellular manners, such as Botrytis cinerea, Candida albicans, Penicillium brevicompactum, Trichoderma harzianum, and Helminthosporum solani (Castro et al. 2014; Ahmad et al. 2013; Mishra et al. 2011; Tripathi et al. 2014; Kumar et al. 2008). However, the fungal species reported for AuNP biosynthesis are still limited (Kitching et al. 2015).

AuNPs possess a high catalytic activity in the reduction of organic contaminants in water owing to their large specific surface area, plenty of active sites, and low coordination number (Narayanan and Sakthivel 2011). As is well-known, 4nitrophenol (4-NP) is one of the industrial pollutants with teratogenetic, carcinogenic, and mutagenic toxicities, which is commonly used as a basic composition of various explosives, pesticides, and solvents (Goi and Trapido 2002; Zhao et al. 2015). Previous reports have suggested that the biogenetic AuNPs could effectively catalyze 4-NP reduction in a short span of time at room temperature (Narayanan and Sakthivel 2011; Mishra et al. 2014). In addition, the biosynthesized AuNPs usually present much better catalytic activity than AuNPs synthesized by chemical methods (Das et al. 2012). Thus, biological synthesis of AuNPs provides a nontoxic and feasible method for 4-NP degradation.

In this study, a green and cost-effective approach for the synthesis of AuNPs by cells (cells-AuNPs) and cell-free extracts (extracts-AuNPs) of the fungus Mariannaea sp. was reported for the first time. The fungus Mariannaea was isolated from activated sludge of laboratory reactor, which has been widely found in leaves of conifer trees, decaying wood, and soil (Okuda and Yamamoto 2000; Cai et al. 2010; Zeng and Zhuang 2014; Tang et al. 2012). As far as we know, there is no report on the AuNPs synthesized by Mariannaea sp. Herein, the effects of initial gold ion concentration and $\mathrm{pH}$ on AuNP synthesis were investigated. The as-synthesized AuNPs were analyzed by UV-vis spectroscopy, transmission electron microscopy (TEM), X-ray diffraction (XRD), dynamic light scattering (DLS), and Fourier transform infrared spectroscopy (FTIR). The catalytic activities of cells-AuNP and extracts-AuNP bioconjugates were also evaluated for the reduction of 4-NP in the presence of $\mathrm{NaBH}_{4}$.

\section{Materials and methods}

\section{Chemicals and culture media}

Activated sludge was collected from the secondary sedimentation tank of Chunliu river wastewater treatment plant (Dalian, China). Gold(III) chloride trihydrate $\left(\mathrm{HAuCl}_{4}\right.$. $3 \mathrm{H}_{2} \mathrm{O}$ ) was purchased from J\&K Scientific Ltd. (Shanghai, China). 4-NP was obtained from Sinopharm Chemical Regent Beijing Co., Ltd. (China). All other reagents were of analytical grade.

The synthetic wastewater used in the bioreactor consisted of $20 \mathrm{mg} / \mathrm{L} \mathrm{KH} \mathrm{KO}_{4}, 90 \mathrm{mg} / \mathrm{L} \mathrm{NH} \mathrm{PH}_{4} \mathrm{Cl}, 10 \mathrm{mg} / \mathrm{L} \mathrm{NaCl}$, $12.5 \mathrm{mg} / \mathrm{L} \mathrm{MgSO}{ }_{4} \cdot 7 \mathrm{H}_{2} \mathrm{O}, 12 \mathrm{mg} / \mathrm{L} \mathrm{CaCl} 2,10 \mathrm{mg} / \mathrm{L} \mathrm{FeSO}_{4}$. $7 \mathrm{H}_{2} \mathrm{O}$, and $500 \mathrm{mg} / \mathrm{L}$ glucose. The culture medium used for the isolation and cultivation of strains was the modified Martin medium, which contained $1.0 \mathrm{~g} / \mathrm{L} \mathrm{NH}_{4} \mathrm{SO}_{4}, 1.0 \mathrm{~g} / \mathrm{L}$ $\mathrm{K}_{2} \mathrm{HPO}_{4}, 0.5 \mathrm{~g} / \mathrm{L} \mathrm{MgSO}{ }_{4} \cdot 7 \mathrm{H}_{2} \mathrm{O}$, and $1.0 \mathrm{~g} / \mathrm{L}$ glucose. Solid medium was prepared by adding $20 \mathrm{~g} / \mathrm{L}$ agar to the modified Martin medium. The modified Martin media were autoclaved at $115^{\circ} \mathrm{C}$ for $20 \mathrm{~min}$ prior to use.

\section{Isolation and identification of Mariannaea sp. HJ}

A sequencing batch reactor (SBR) was constructed and seeded with the activated sludge, which was domesticated with the synthetic wastewater containing $50 \mathrm{mg} / \mathrm{L}$ tetracycline for 2 months. Subsequently, $1 \mathrm{~mL}$ reaction mixture was plated on the modified Martin agar medium supplemented with $50 \mathrm{mg} / \mathrm{L}$ tetracycline and incubated at $30{ }^{\circ} \mathrm{C}$ for 3 days. A single colony was picked and cultured in the modified Martin medium containing $50 \mathrm{mg} / \mathrm{L}$ tetracycline at $30^{\circ} \mathrm{C}$ with continuous shaking for $48 \mathrm{~h}$. Then, the culture was further plated on the modified Martin agar medium with tetracycline $(50 \mathrm{mg} / \mathrm{L})$. After about 1-month screening, the fastestgrowing fungus was selected and designated as HJ. The colony pattern of strain $\mathrm{HJ}$ was observed via potato dextrose agar (PDA) plates, and the morphological characteristics were observed by scanning electron microscopy (SEM, Hitachi SU8020, Japan).

The 26S ribosomal RNA (rRNA) gene of the strain HJ was amplified and sequenced by TaKaRa Biotechnology Co., Ltd. (Dalian, China). The obtained sequence was analyzed using the BLAST program in NCBI and aligned with reference sequences using Clustal X 1.8. The aligned sequences were used to construct a phylogenetic tree using the neighbor-joining method by MEGA 5.1.

\section{Biosynthesis of AuNPs by cells and cell-free extracts of strain $\mathbf{H J}$}

The fungal strain $\mathrm{HJ}$ was inoculated into the modified Martin medium and incubated at $30^{\circ} \mathrm{C}$ with shaking. After $48 \mathrm{~h}$ of 
fermentation, the culture medium was filtered with qualitative filter papers and washed thoroughly with sterile ultrapure water for three times. Then, 0.5-g fungal mycelia (wet weight) were resuspended in $5 \mathrm{~mL}$ of $\mathrm{HAuCl}_{4}$ solution with an initial gold ion concentration of $2.0 \mathrm{mM}$ and incubated at $30^{\circ} \mathrm{C}$ for $12 \mathrm{~h}$ in dark condition. At a certain time interval, the mixture was collected and treated by sonication for $30 \mathrm{~min}$ (Ultrasonic Processor CPX 750, USA) to disrupt the fungal mycelia and release the nanoparticles into aqueous solutions. The mixture was then centrifuged at $3000 \times g$ for $10 \mathrm{~min}$ to remove the cell debris, and the supernatant was monitored using UV-vis spectroscopy. Different $\mathrm{HAuCl}_{4}$ concentrations of $0.1,0.5,1.0$, 2.0 , and $3.0 \mathrm{mM}$ were used to check the effects of initial gold ion concentration on cells-AuNP synthesis. The fungal mycelia resuspended in $2.0 \mathrm{mM} \mathrm{HAuCl}_{4}$ solutions were incubated at $\mathrm{pH} 2,4,6,7,8$, and 10 to investigate the effects of $\mathrm{pH}$, which were adjusted using $\mathrm{KOH}$ or $\mathrm{HCl}$.

For extracts-AuNPs, the harvested mycelia were resuspended in phosphate sodium buffer (PBS, $50 \mathrm{mM}, \mathrm{pH} 7$ ) and then lysed by sonication for $40 \mathrm{~min}$. The cell debris were removed by centrifugation at $10,000 \times g$ for $20 \mathrm{~min}$, and the supernatant was filtered through $0.45-\mu \mathrm{m}$ Millipore filters, which was donated as the cell-free extracts. The concentration of protein in the cell-free extracts was regulated to $100 \mathrm{mg} / \mathrm{L}$ based on Bradford assays (Bradford 1976). Biosynthesis of extracts-AuNPs was performed by mixing the cell-free extracts with $2.0 \mathrm{mM} \mathrm{HAuCl}_{4}$. Then, the reaction mixture was incubated at $30{ }^{\circ} \mathrm{C}$ for 6 days in dark condition. Different $\mathrm{HAuCl}_{4}$ concentrations of $0.1,0.5,1.0,2.0,3.0$, and $5.0 \mathrm{mM}$ were added to PBS to investigate the effects of initial gold ion concentration on extracts-AuNP synthesis. As for the effects of solution $\mathrm{pH}$, reactions were conducted at different $\mathrm{pH}$ of $5,6,7,8$, and 9 , which were adjusted using $\mathrm{Na}_{2} \mathrm{HPO}_{4}$ and $\mathrm{NaH}_{2} \mathrm{PO}_{4}$ in PBS. The control experiments were carried out without the addition of $\mathrm{HAuCl}_{4}$. The formation of AuNPs was monitored by UV-vis spectroscopy, and all experiments were carried out in triplicate.

\section{Characterization of cells-AuNPs and extracts-AuNPs}

The color change of the reaction solution was the preliminary indicator of AuNP formation. Further, the formation of AuNPs was monitored by UV-vis spectroscopy (Metash UV9000, Shanghai, China) at a resolution of $1 \mathrm{~nm}$ between 400 and $800 \mathrm{~nm}$. TEM observation was carried out by Tecnai G220 S-Twin (FEI, USA) at an accelerating voltage of $120 \mathrm{kV}$. XRD analysis was operated using D/max-2400 Xray diffractometer (Rigaku, Japan) with $\mathrm{Cu} \mathrm{K} \alpha$ radiation $(\lambda=0.1541 \mathrm{~nm})$. About 20 representative TEM images including more than 400 particles were used to obtain the histograms of AuNPs. DLS measurement was performed by Zetasizer Nano ZS (Marvin Instruments, UK) to analyze the average particle size, polydispersity, and zeta potential of
AuNPs. The diffracted patterns were recorded at $2 \theta$ from $20^{\circ}$ to $90^{\circ}$ with a scanning speed of $5 \% \mathrm{~min}$. FTIR spectra of cells-AuNPs, extracts-AuNPs, and the cells and the cell-free extracts of strain HJ were collected with a Shimadzu IRPrestige-21 FTIR spectrophotometer (Japan) with the wavelength ranging from 750 to $4000 / \mathrm{cm}$. The gold concentration in the reaction solutions after the biosynthesis of AuNPs was measured using a Perkin-Elmer Optima 2000DV (USA) inductively coupled plasma-optical emission spectrometer (ICP-OES).

\section{Toxicity of AuNPs against Arthrobacter sp. W1 and Escherichia coli BL21 (DE3)}

The toxicity of both cells-AuNPs and extracts-AuNPs was investigated using two tested bacteria, Arthrobacter sp. W1 (gram-positive bacteria) and Escherichia coli BL21 (DE3) (gram-negative bacteria), which were derived from our lab. The paper disc diffusion method was performed to evaluate the antibacterial activities of $\mathrm{Au}^{3+}$, cells-AuNPs, and extractsAuNPs. The two bacteria were grown aerobically in LuriaBertani (LB) broth until they reached the late log phase, and then $200 \mu \mathrm{L}$ of each bacterium was inoculated on LB agar plates evenly. Subsequently, the paper discs containing the sample solution were placed at the LB agar plates and incubated for $24 \mathrm{~h}$ at $37^{\circ} \mathrm{C}$. The inhibition zone was the standard measure of the antibacterial activity (Huang et al. 2016).

\section{Catalytic activities of cells-AuNPs and extracts-AuNPs in the reduction of $4-\mathrm{NP}$}

For catalytic reactions, the cells-AuNPs and extracts-AuNPs were used for the reduction of 4-NP with an excess quantity of $\mathrm{NaBH}_{4}$. Typically, $50 \mu \mathrm{L}$ cells-AuNPs $(0.394 \mathrm{mg} / \mathrm{mL})$ or $101 \mu \mathrm{L}$ extracts-AuNPs $(0.195 \mathrm{mg} / \mathrm{mL})$ were mixed with $100 \mu \mathrm{L} 0.1 \mathrm{M} \mathrm{NaBH}_{4}$ and $100 \mu \mathrm{L} 2.0 \mathrm{mM} 4-\mathrm{NP}$, respectively. Sterile ultrapure water was added to give a final volume of $2 \mathrm{~mL}$. The reduction of 4-NP was monitored by measuring the UV-vis spectra of the mixture at a time interval of $1 \mathrm{~min}$ for cells-AuNP system and $10 \mathrm{~s}$ for extracts-AuNP system. Blank controls without the addition of AuNPs were also conducted. Each reaction was performed in triplicate, and the average value was used for calculation.

\section{Results}

\section{Isolation and identification of Mariannaea sp. HJ}

A fungal strain, designated as HJ, was isolated from the activated sludge. As shown in Fig. 1a, the colony of the strain HJ on PDA agar plate was zonate- and mat-like with a regular edge. SEM images of the strain HJ showed that the 
Fig. 1 Morphological and phylogenetic analyses of strain HJ. a Colonial morphology of strain HJ on PDA agar plate. b SEM images of strain HJ. The inset shows the spores of strain HJ. c Phylogenetic tree of strain $\mathrm{HJ}$ and related species based on 26S rRNA gene sequence analysis
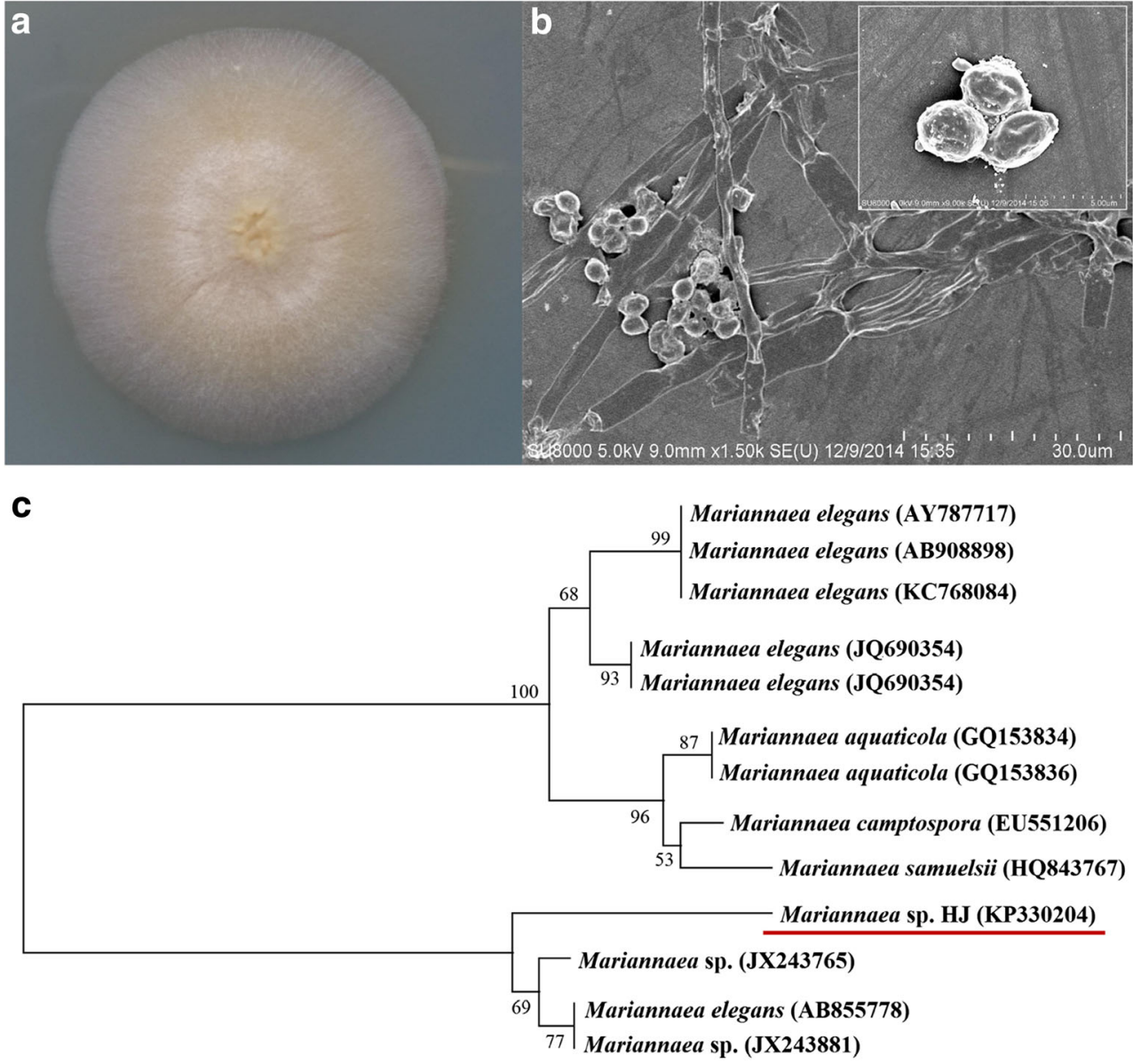

conidiophores were spheroidic and formed in clusters (Fig. 1b). To taxonomically identify the strain HJ, the $26 \mathrm{~S}$ rRNA gene was amplified and a 521-bp amplicon was obtained, which was deposited in GenBank under the accession number KP330204. Based on the sequence analysis, the strain HJ exhibited high similarity (99\%) to several Mariannaea sp. strains. Therefore, the strain $\mathrm{HJ}$ was identified as Mariannaea sp. and deposited in the China General Microbiological Culture Collection Center under accession number CGMCC 10030. The phylogenetic trees of the isolated HJ and other Mariannaea sp. strains are shown in Fig. 1c.

\section{Biosynthesis and characterization of cells-AuNPs}

When the mycelium of the strain $\mathrm{HJ}$ was exposed to $\mathrm{HAuCl}_{4}$ aqueous solution, a rapid color change of the reaction solution from pale yellow to purple was observed within $3 \mathrm{~h}$. In the meanwhile, a strong absorption peak at around $543 \mathrm{~nm}$ was observed due to the surface plasmon resonance (SPR) of AuNPs (Fig. 2a) (Eustis and El-Sayed 2006). The SPR peak intensity gradually increased versus the incubation time and reached maximum after $9 \mathrm{~h}$. Further increasing the incubation time, almost no enhancement of SPR intensity was observed. In the blank experiments, no color change or absorption peak was observed.

The effects of the initial gold ion concentration and $\mathrm{pH}$ on cells-AuNP synthesis are depicted in Figs. 2b and S1. When the initial gold ion concentration was $0.1 \mathrm{mM}$, no significant SPR peak was observed. Then, with the initial gold ion concentration increasing from 0.5 to $2.0 \mathrm{mM}$, the intensity of SPR peaks at around $543 \mathrm{~nm}$ increased without an obvious shift in peak position (Fig. S1a). Further increasing the initial gold ion concentration to $3.0 \mathrm{mM}$, the SPR peak intensity showed a significant decrease, indicating the lower production of cellsAuNPs (Pimprikar et al. 2009). The cells of the strain HJ could synthesize AuNPs at a broad pH range (4-10), and pH 7 was the most suitable (Fig. S1b). When the $\mathrm{pH}$ was below or above 7, the SPR peak intensity decreased slightly, and the SPR peaks had no change in position and shape except for $\mathrm{pH} 2$. When $\mathrm{pH} 2$ was used, no SPR peak was observed, indicating no cells-AuNP formation. Thus, $2.0 \mathrm{mM} \mathrm{HAuCl}_{4}$ and $\mathrm{pH} 7$ were preferable to cells-AuNP synthesis.

TEM measurement was carried out to estimate the morphology and size of cells-AuNPs (Fig. 3a). From the 

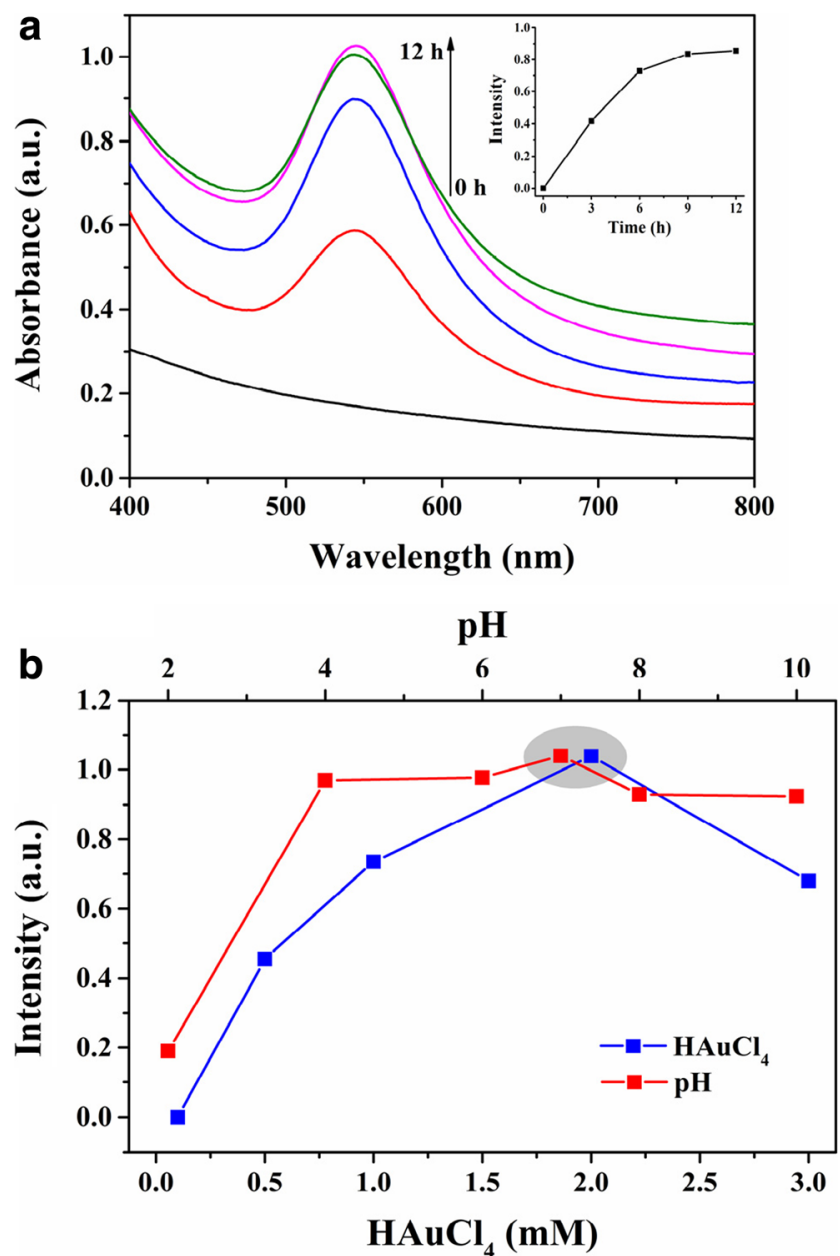

Fig. 2 Biosynthesis of AuNPs by cells of strain HJ. a UV-vis spectra of AuNPs synthesized at various times with a time interval of $3 \mathrm{~h}$. The inset shows the maximum intensity of SPR peaks at different incubation times. b Simultaneous effects of $\mathrm{pH}$ and $\mathrm{HAuCl}_{4}$ concentration on SPR peak intensities of AuNPs

representative TEM images, it was found that multiple shapes of nanoparticles were produced, including sphere, trigon, pentagon, hexagon, and irregular shapes. Through measuring more than 400 particles, the size of cells-AuNPs was calculated to be in the range of $4-120 \mathrm{~nm}$ and the average size was $37.4 \mathrm{~nm}$, with a sigma value of 3.29 . The large variation in particle size was attributed to the presence of trigon, hexagon, and irregular shapes. DLS data indicated that the average size of cells-AuNPs was $104.3 \mathrm{~nm}$, which was larger than that observed by TEM. Polydispersity index (PDI) of cellsAuNPs was 0.379 , indicating the formation of nano-sized monodispersed particles. The zeta potential measurement showed a mean value of $-12.95 \mathrm{mV}$ for cells-AuNPs, indicating the stability of the synthesized nanoparticles.

XRD analysis was performed to investigate the crystal structure of cells-AuNPs (Fig. 3b). Five distinct intense diffraction peaks were detected at $2 \theta=238.02^{\circ}, 44.19^{\circ}, 64.46^{\circ}$, $77.51^{\circ}$, and $81.68^{\circ}$, corresponding to the (111), (200), (220), (311), and (222) planes of the standard face-centered cubic a
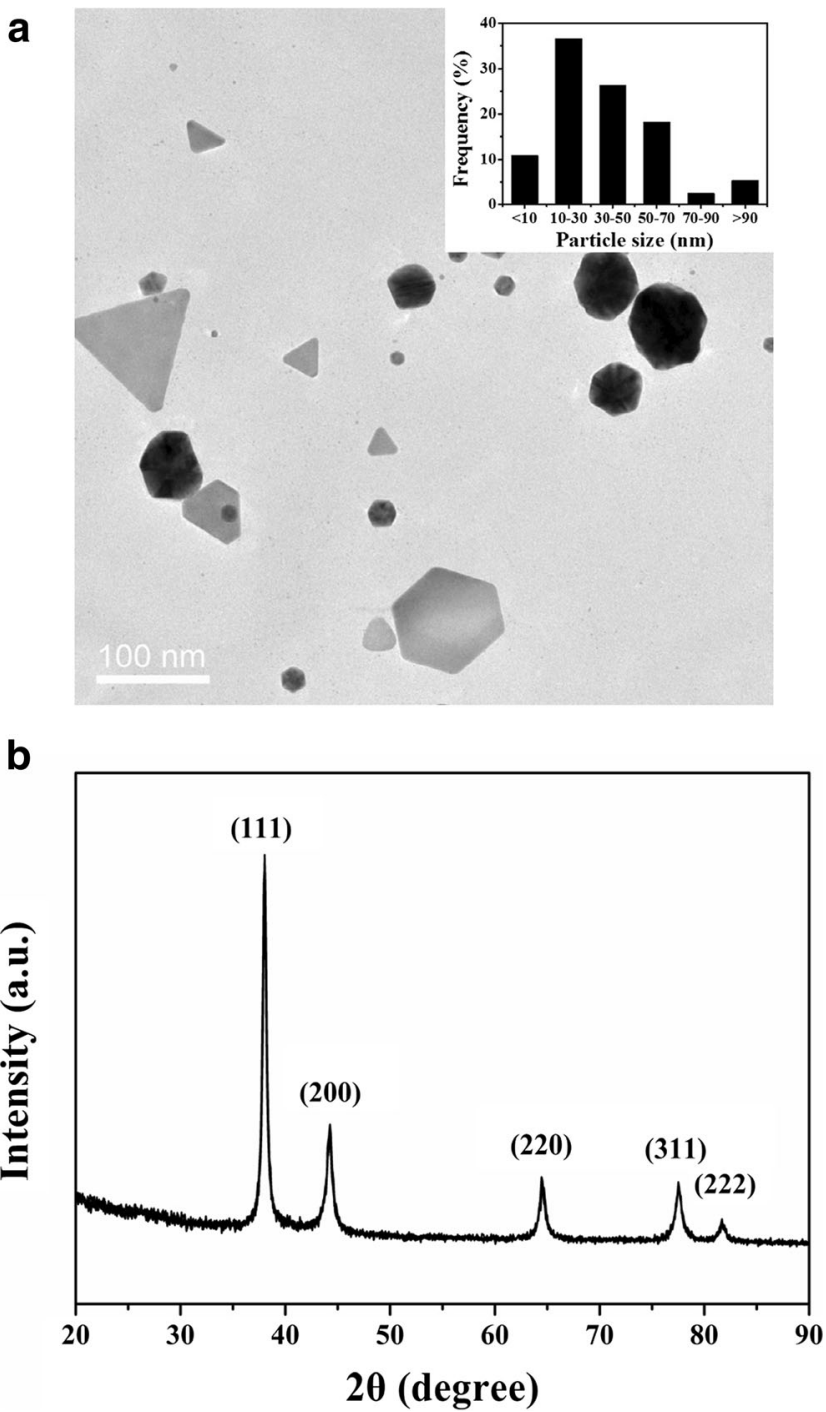

Fig. 3 TEM (a) and XRD (b) analyses of AuNPs synthesized by strain $\mathrm{HJ}$ cells. The inset shows the size distribution histogram determined from TEM images

phase of gold, respectively (JCPDS No. 04-0783). The diffraction peak corresponding to the (111) phase was distinctly more intense than the rest of peaks, indicating that (111) was the primary orientation. No impure peaks were detected, suggesting the high purity of the biogenetic AuNPs.

\section{Biosynthesis and characterization of extracts-AuNPs}

Biosynthesis of extracts-AuNPs was revealed from the changes in color and SPR peak of the reaction solution (Fig. 4a). The color of the reaction solution changed from pale yellow to purple-red within 1 day, and a weak SPR peak emerged at about $532 \mathrm{~nm}$, indicating the formation of AuNPs (Ahmad et al. 2013). Incubation for a longer time led to the increase in color intensity and SPR peak intensity, which reached saturation after 5 days. 

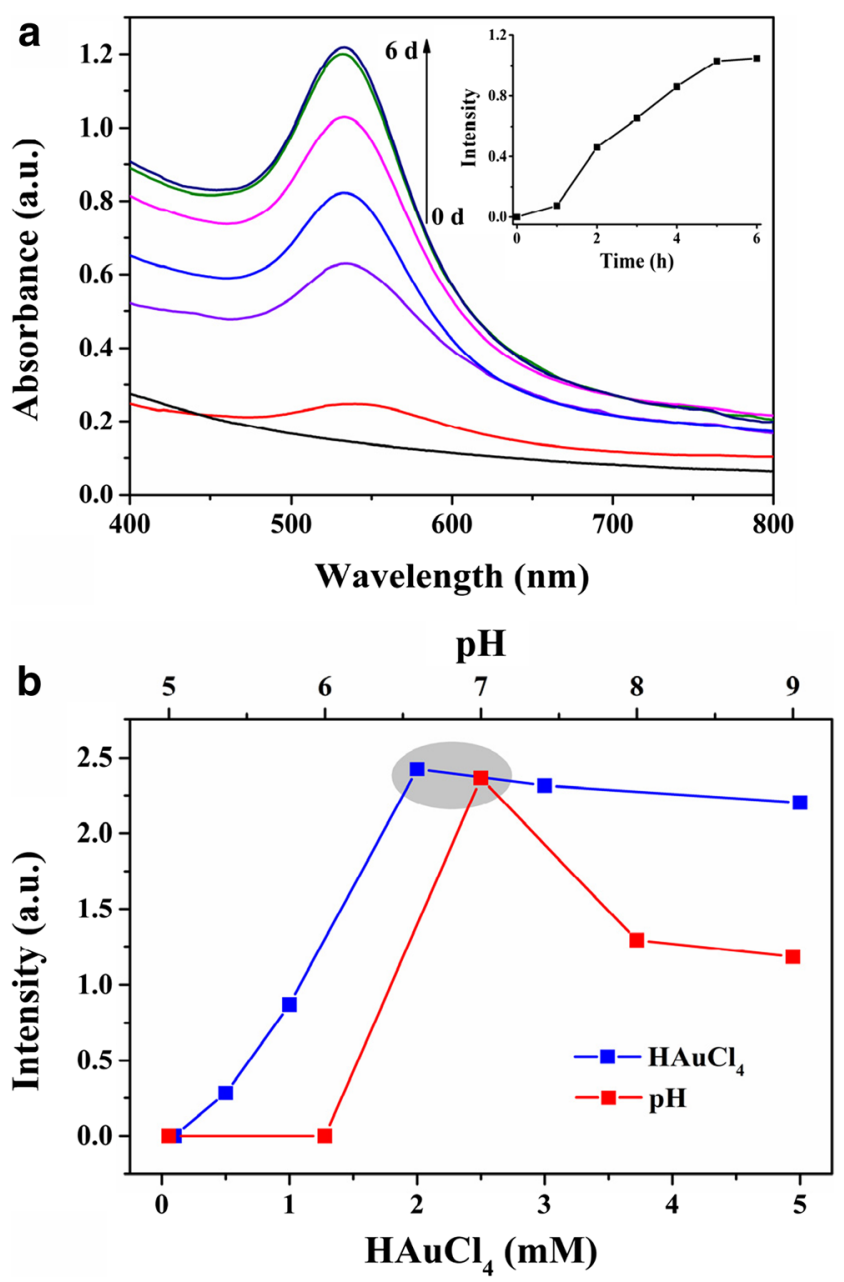

Fig. 4 Biosynthesis of AuNPs by cell-free extracts of strain HJ. a UV-vis spectra of AuNPs synthesized at various times with a time interval of 1 day. The inset shows the maximum intensity of SPR peaks at different incubation times. b Simultaneous effects of $\mathrm{pH}$ and $\mathrm{HAuCl}_{4}$ concentration on SPR peak intensities of AuNPs

The effects of the initial gold ion concentration and $\mathrm{pH}$ on extracts-AuNP synthesis are shown in Figs. $4 \mathrm{~b}$ and S2. When $0.1 \mathrm{mM} \mathrm{HAuCl}_{4}$ was used, no SPR peak was observed. At $\mathrm{HAuCl}_{4}$ concentration of $0.5 \mathrm{mM}$, an obvious SPR peak at around $532 \mathrm{~nm}$ occurred, which slightly redshifted to about $556 \mathrm{~nm}$ with the increase of $\mathrm{HAuCl}_{4}$ concentration to $5.0 \mathrm{mM}$ (Fig. S2a). It was observed that with $2.0 \mathrm{mM} \mathrm{HAuCl}_{4}$ used, the SPR peak was stronger and narrower than others, indicating the formation of extracts-AuNPs with higher production and smaller size distribution (Pimprikar et al. 2009). As shown in Fig. S2b, no absorption peaks of the reaction solution were observed at pH 5 and $\mathrm{pH} 6$. At pH 7, a distinct SPR peak was recorded at about $535 \mathrm{~nm}$, but then, the intensity of SPR peaks decreased with the increase of $\mathrm{pH}$ (8 and 9). Therefore, the maximum intensity of SPR peak was obtained at $2.0 \mathrm{mM}$ $\mathrm{HAuCl}_{4}$ and $\mathrm{pH} 7$ (Fig. 4b).

TEM images revealed that the extracts-AuNPs were almost spherical and pseudo-spherical with a particle size distribution of 4 to $25 \mathrm{~nm}$, and the average size was calculated to be $11.7 \mathrm{~nm}$ (Fig. 5a). Corresponding histograms indicated that there was a good uniform size distribution with $57 \%$ of extracts-AuNPs distributing between 10 and $15 \mathrm{~nm}$ with a sigma value of 25.49. According to DLS analysis, the average size of extracts-AuNPs was $45.4 \mathrm{~nm}$, and the polydispersity index (PDI) was 0.476. Meanwhile, the zeta potential value of extracts-AuNPs was $-43.7 \mathrm{mV}$.

XRD pattern of extracts-AuNPs exhibited three peaks at $2 \theta$ values of $37.94^{\circ}, 44.06^{\circ}$, and $63.94^{\circ}$, which were indexed to the (111), (200), and (220) reflections of the face-centered cubic phase of metal gold, respectively (JCPDS No. 040783) (Fig. 5b). It was noted that the diffraction peak corresponding to the (111) plane was more intense than the others, indicating that the (111) plane was the primary orientation.

\section{FTIR analysis of cells-AuNPs and extracts-AuNPs}

FTIR analysis was carried out to identify the possible functional groups of the biomolecules that were involved in the formation of cells-AuNPs and extracts-AuNPs. As shown in Fig. 6a, it was observed that both strain HJ cells and cellsAuNPs showed obvious absorption bands at $\sim 3440, \sim 2930$, $\sim 2850, \sim 1645, \sim 1540$, and $\sim 1040 / \mathrm{cm}$. The strong absorption band at $\sim 3440 / \mathrm{cm}$ was attributed to the stretching vibration of $\mathrm{O}-\mathrm{H}$ groups present in carbohydrates or proteins (Shi et al. 2015). The two bands observed at $\sim 2930$ and $\sim 2850 / \mathrm{cm}$ referred to aliphatic $\mathrm{C}-\mathrm{H}$ stretching vibration. The bands at $\sim 1645$ and $\sim 1540 / \mathrm{cm}$ were assigned to amide I and amide II, respectively (Zhang et al. 2016). The band at $\sim 1040 / \mathrm{cm}$ corresponded to $\mathrm{C}-\mathrm{N}$ stretching of aliphatic amines. The other bands observed in the FTIR spectra of strain $\mathrm{HJ}$ cells located at $\sim 1750$ and $\sim 1400 / \mathrm{cm}$ were confirmed to COO- symmetric stretching vibration from carboxyl side groups (Reddy et al. 2012), which were not observed in that of cells-AuNPs. Similarly, the FTIR spectra of cell-free extracts and extractsAuNPs closely resembled the one of strain HJ cells, which showed obvious absorption bands at $\sim 3440, \sim 2930, \sim 2850$, $\sim 1745, \sim 1645, \sim 1540, \sim 1400$, and $\sim 1040 / \mathrm{cm}$ (Fig. $6 b$ ). The slight shifts of absorption bands should be due to the reduction of $\mathrm{Au}^{3+}$ to $\mathrm{Au}^{0}$ and the capping of AuNPs by some biomolecules.

\section{Toxicity of AuNPs}

The antibacterial effect of the synthesized nanoparticles was evaluated against gram-positive (Arthrobacter sp. W1) and gram-negative (E. coli) bacterial strains. $\mathrm{Au}^{3+}$ was used as control. The inhibition zone results using disc diffusion assay are shown in Fig. S4. It was evident from the zone of inhibition that $\mathrm{Au}^{3+}$ possessed potent bactericidal activity, but the cells-AuNPs and extracts-AuNPs showed no apparent antibacterial activity. 
a

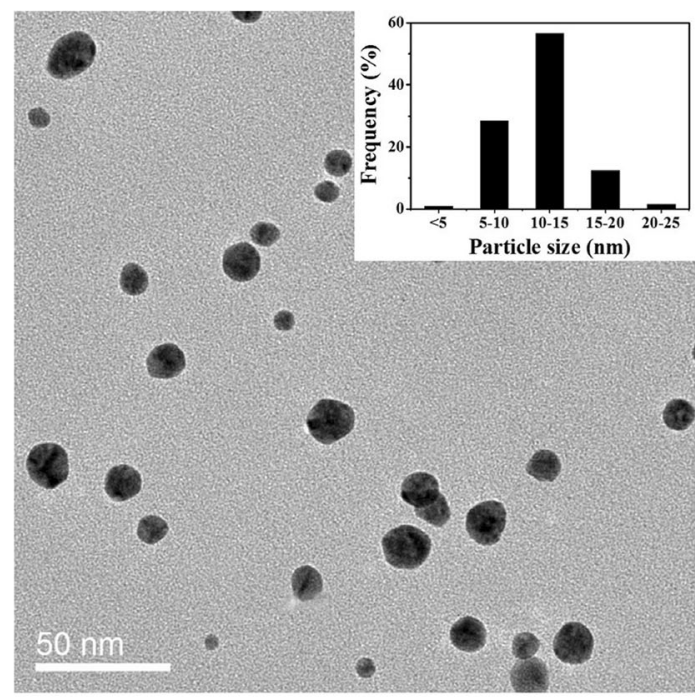

b

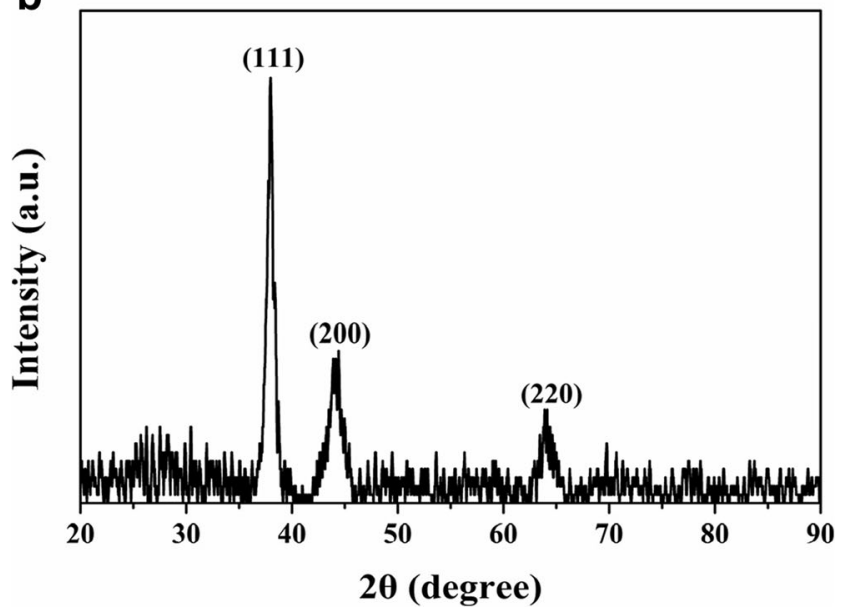

Fig. 5 TEM (a) and XRD (b) analyses of AuNPs synthesized by cell-free extracts of strain HJ. The inset shows the size distribution histogram determined from TEM images

\section{Catalytic activities of cells-AuNPs and extracts-AuNPs}

The catalytic activities of cells-AuNPs and extracts-AuNPs were evaluated in the reduction of 4-NP using excess $\mathrm{NaBH}_{4}$. In aqueous media containing $0.1 \mathrm{mM} 4-\mathrm{NP}$ and $100 \mathrm{mM} \mathrm{NaBH}_{4}, \mathrm{UV}$-vis spectra showed an absorption peak at $400 \mathrm{~nm}$ due to the formation of 4-nitrophenolate ion (Das et al. 2012; Narayanan and Sakthivel 2011). After the addition of cells-AuNP $(0.394 \mathrm{mg} / \mathrm{mL})$ or extracts-AuNP $(0.195 \mathrm{mg} /$ $\mathrm{mL}$ ) bioconjugates, the intensity of absorption peaks at $400 \mathrm{~nm}$ decreased rapidly, and a new peak appeared at around $300 \mathrm{~nm}$ (Fig. S3), corresponding to the reduction products, 4aminophenol (4-AP). For cells-AuNP and extracts-AuNP systems, the color of the reaction mixture gradually changed from yellow to colorless within 480 and $120 \mathrm{~s}$, respectively, while the control experiment without AuNPs had no color change even after several days. Since the concentration of $\mathrm{NaBH}_{4}$ was significantly higher than that of 4-NP, the apparent rate

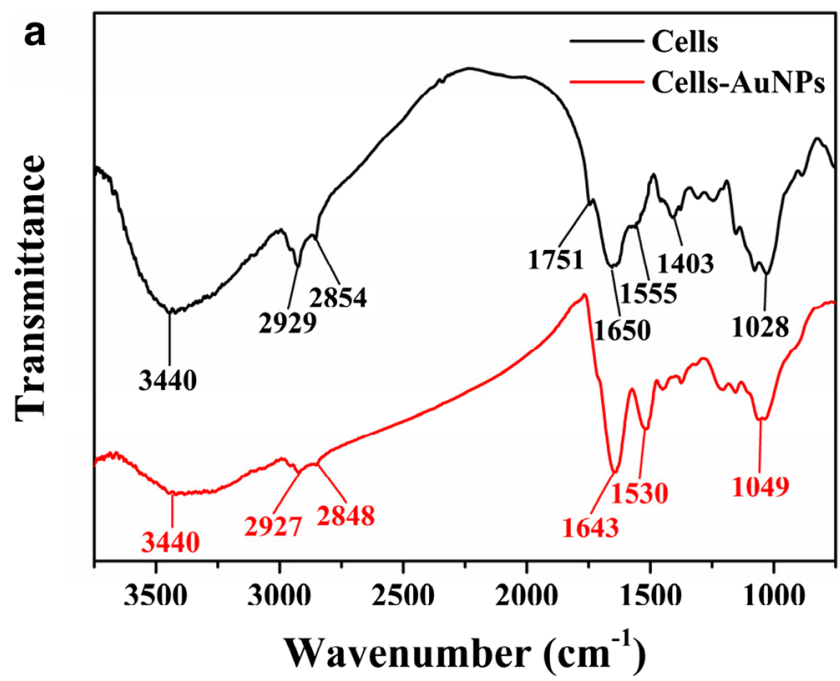

b

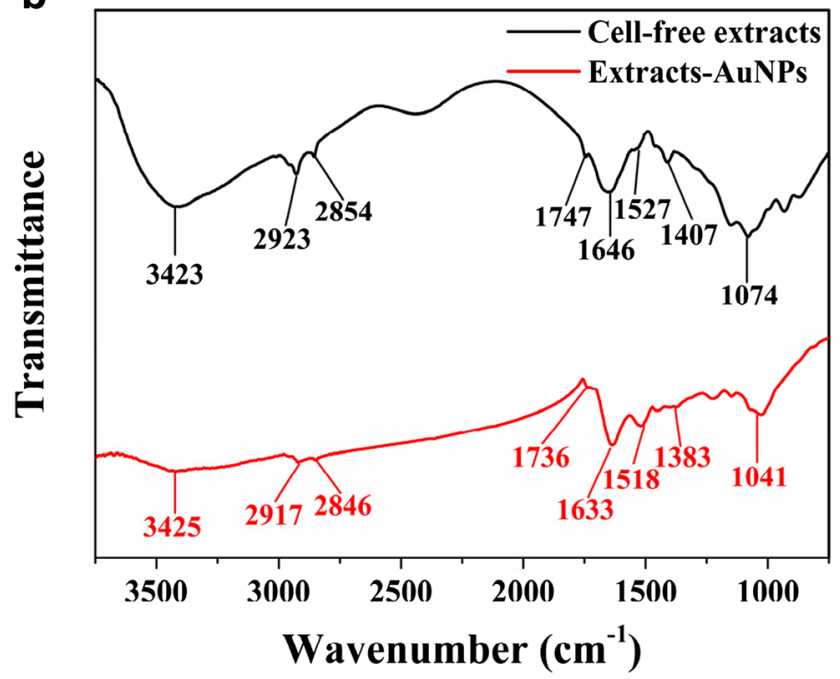

Fig. 6 FTIR spectra of cells-AuNPs (a) and extracts-AuNPs (b)

constant $(k)$ could be estimated by the pseudo-first-order approach (Gu et al. 2014). Figure 7 shows the plots of $A_{t} / A_{0}$ and $\ln \left(A_{t} / A_{0}\right)$ versus time, and good linear correlations were observed. $R^{2}$ values of Fig. $7 \mathrm{a}, \mathrm{b}$ were 0.98 and 0.9933 , and the rate constants for 4-NP reduction catalyzed by cells-AuNPs and extracts-AuNPs were calculated to be $5.7 \times 10^{-3}$ and $24.7 \times 10^{-3} / \mathrm{s}$, respectively.

\section{Discussion}

Mariannaea species were previously reported to be widely existing in the soil, rotten wood, and leaves of conifer trees (Okuda and Yamamoto 2000; Cai et al. 2010; Zeng and Zhuang 2014; Tang et al. 2012). Some natural organic compounds with antimicrobial activities could be isolated from the fungus Mariannaea, such as prenylated phenylpropanoids (Fukuda et al. 2011). However, very limited features of the 


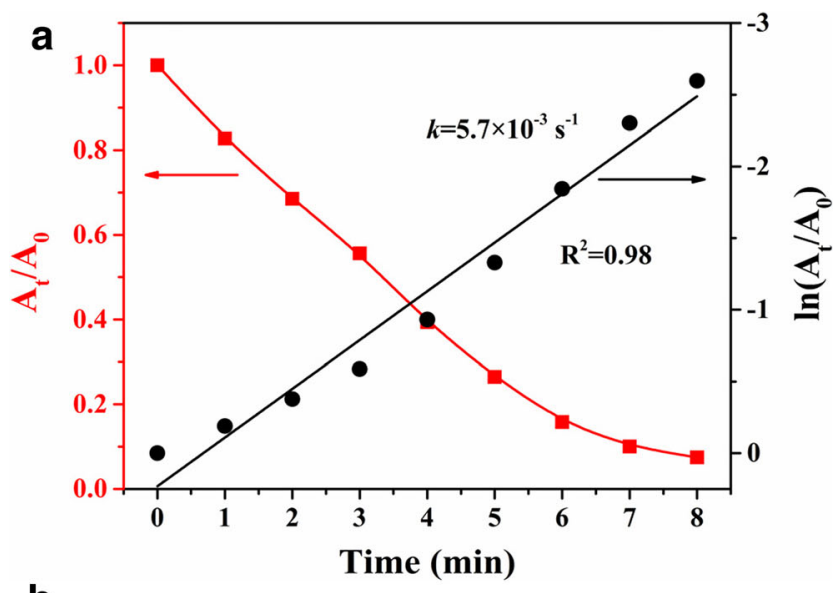

b

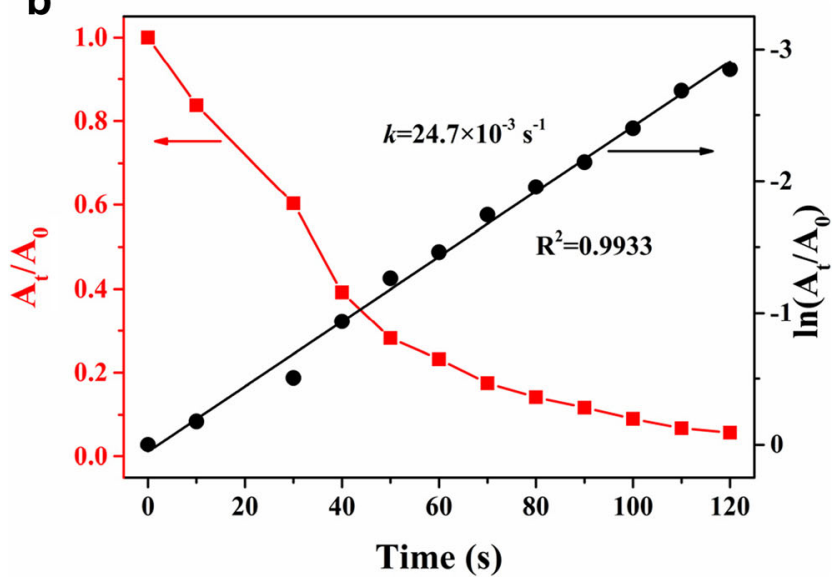

Fig. 7 Catalytic reduction of 4-NP by cells-AuNPs (a) and extractsAuNPs (b)

fungus Mariannaea have been characterized, and no literature concerning the biosynthesis of metal nanoparticles by Mariannaea spp. has been reported. Herein, the biosynthesis of AuNPs using cells and cell-free extracts of Mariannaea sp. HJ was investigated for the first time.

Previous studies have postulated that fungi could secrete abundant intracellular or extracellular proteins, which could act as reducing, capping, and stabilizing agents for the synthesis of AuNPs (Kitching et al. 2015). But there were still relatively few studies concerning the synthesis of AuNPs by fungi. For example, Das et al. (2012) reported the formation of spherical AuNPs ranging from 5 to $65 \mathrm{~nm}$ using Rhizopus oryzae protein extracts, while the cell-free extracts of Trichoderma sp. could synthesize AuNPs with the majority being spherical $(60 \%)$ in the range of 20-30 nm (Mishra et al. 2014). The cells of Magnusiomyces ingens LH-F1 could produce various shaped nanoparticles with an average particle size of $80.1 \mathrm{~nm}$, and some plate-shaped particles larger than $200 \mathrm{~nm}$ were also observed (Zhang et al. 2016). Our results indicated that both cells and cell-free extracts of Mariannaea sp. HJ exhibited good abilities for the synthesis of AuNPs, providing a novel microbial resource for the green synthesis of metal nanoparticles.
Different reaction parameters, such as gold ion concentration and $\mathrm{pH}$, had a significant impact on the reduction and stabilization of AuNPs. The formation of both cells-AuNPs and extracts-AuNPs was favored at $2 \mathrm{mM} \mathrm{HAuCl}_{4}$. The nucleation and growth processes of nanocrystal were generally important for the formation of AuNPs (Jana et al. 2001). Lower $\mathrm{HAuCl}_{4}$ concentration might decrease the formation of initial metal nuclei, resulting in the low production of biosynthesized AuNPs. But higher $\mathrm{HAuCl}_{4}$ concentration could result in the formation of AuNPs with multiple shapes and large size, leading to the decrease in intensity and redshift of the SPR peak (Mishra et al. 2016). Mishra et al. (2011) reported that the concentration of gold salt had an effect on the size and shape of biosynthesized AuNPs, and low or high $\mathrm{HAuCl}_{4}$ concentration would prevent the formation of AuNPs with uniform size and high yield. Meanwhile, a neutral condition was more suitable for the formation of cells-AuNPs and extracts-AuNPs. Acidic and alkaline conditions might change the activity of proteins or affect the aggregation of nanoparticles, posing negative impacts on the biosynthesis of AuNPs (Mishra et al. 2016). Sneha et al. (2010) reported that the aggregation of AuNPs was observed at low $\mathrm{pH}$, resulting in the formation of large nanoparticles and platelets.

XRD analysis revealed the face-centered cubic phase of cells-AuNPs and extracts-AuNPs with the (111) plane as the basal plane, while the shape and size of these nanoparticles were quite different as shown by TEM analysis. The cellsAuNPs contained various shapes with a wide size distribution $(4-120 \mathrm{~nm})$ and larger average particle size $(37.4 \mathrm{~nm})$, while the extracts-AuNPs were more uniform with a narrower size distribution $(4-25 \mathrm{~nm})$ and smaller average particle size $(11.7 \mathrm{~nm})$. The sigma value of extracts-AuNPs was 7.7-fold higher than that of cells-AuNPs, further indicating the better uniform size distribution of extracts-AuNPs. However, the particle size observed in the DLS measurement was larger than that in TEM, which was probably due to the enveloping of bioorganic compounds on the AuNPs (Zhang et al. 2016). In addition, the biosynthesis rate of cells-AuNPs was much faster than that of extracts-AuNPs and many other reported AuNPs synthesized by different fungi, such as M. ingens LHF1 (Zhang et al. 2016) and Verticillium sp. (Mukherjee et al. 2001), indicating that the cells of the strain HJ were more favorable to the reduction of $\mathrm{Au}^{3+}$ to $\mathrm{Au}^{0}$. Xie et al. (2007) indicated that the reduction rate greatly affected the size and morphology of AuNPs and a slow reduction process was generally favorable for anisotropic growth and larger nanoparticles, which was in contrast to the present results. Compared with physical and chemical methods, the biosynthesis of AuNPs is considered as an environment-friendly manner without the consumption of high energy and toxic chemical reagents. Since no additional chemical reagents were used in the present study, the reduction and stabilization of AuNPs should be driven by the preexisting biomolecules in the fungal 
Table 1 Comparison of the rate constants of different biogenetic AuNPs for 4-NP catalytic reduction

\begin{tabular}{lllll}
\hline Biological systems & Size $(\mathrm{nm})$ & Morphology & $k\left(10^{-3} / \mathrm{s}\right)$ & References \\
\hline Cylindrocladium floridanum & $5-35$ & Sphere & $0.1-0.5$ & Narayanan and Sakthivel (2011) \\
Sterculia acuminata extracts & 18.8 & Sphere & 1.8 & Bogireddy et al. (2015) \\
Escherichia coli & 50 & Sphere & 0.21 & Srivastava et al. (2013) \\
Pichia pastoris & $14.8 \pm 3.9$ & Sphere & 8.1 & Lin et al. (2013) \\
Breynia rhamnoides extracts & 25 & Sphere & 9.2 & Gangula et al. (2011) \\
Mariannaea sp. & 37.4 & Multiple shapes & 5.7 & This study \\
Mariannaea sp. extracts & 11.7 & Sphere & 24.7 & This study
\end{tabular}

system. It is possible that some biomolecules derived from the fungal cell walls could be used as reducing and capping agents to form the anisotropic nanoparticles (Xie et al. 2007). The capping of polyphenolic constituents in the cell-free extracts might result in the large negative potential value of extractsAuNPs, which could make the nanoparticles more stable (Edison and Sethuraman 2012). The FTIR spectra demonstrated that hydroxyl, amine, and carboxyl groups might play an important role in the formation of both cells-AuNPs and extracts-AuNPs. However, the absence of carboxyl groups in cells-AuNPs suggested that these groups might be mainly involved in the reduction process rather than the capping process. A previous study by Shi et al. (2015) reported that hydroxyl, amine, and carboxyl present in the intracellular protein extracts of Pycnoporus sanguineus were involved in the reduction of $\mathrm{Au}^{3+}$ and stabilization of AuNPs. Zhang et al. (2016) demonstrated that some amide and carboxyl groups originated from $M$. ingens LH-F1 were absorbed on the surface of AuNPs, serving as reducing and capping agents for the formation of AuNPs. However, the mechanism of AuNP biosynthesis was not fully explored and needed further investigation.

The antibacterial test indicated the low toxicity and good biocompatibility of the biosynthesized AuNPs, which could be used as an environment-friendly catalyst for nitroaromatic compound degradation. The cells-AuNPs and extracts-AuNPs possessed excellent catalytic activities for the reduction of 4$\mathrm{NP}$ into 4-AP in the presence of excess $\mathrm{NaBH}_{4}$, and the catalytic rate constant of extracts-AuNPs $\left(24.7 \times 10^{-3} / \mathrm{s}\right)$ was 4.3 fold higher than that of cells-AuNPs $\left(5.7 \times 10^{-3} / \mathrm{s}\right)$. The rate constants of both cells-AuNPs and extracts-AuNPs for 4-NP reduction were comparable with or even higher than that of other biogenetic AuNPs (Table 1). For example, the nanogold biocomposite synthesized by the fungus Cylindrocladium floridanum could catalyze the reduction of 4-NP with rate constants of $0.1-0.5 \times 10^{-3} / \mathrm{s}$ (Narayanan and Sakthivel 2011), while the AuNPs synthesized by Sterculia acuminata extracts could be used for 4-NP reduction with a rate constant of $1.8 \times 10^{-3} / \mathrm{s}$ (Bogireddy et al. 2015). The high catalytic activity of extracts-AuNPs could be associated with their uniform shapes and small particle sizes. According to previous reports, the size and shape of nanoparticles could influence the available active surface area for the absorption of reactants (4$\mathrm{NP}$ and $\mathrm{NaBH}_{4}$ ), which further affected the electron transfer process during 4-NP reduction, leading to differentiated catalytic activities (Kundu et al. 2009a, 2009b). Aromal and Philip (2012) found that the catalytic activity of AuNPs for 4-NP reduction was size-dependent, and the speed of catalytic reduction increased with the decrease in particle size. Reddy et al. (2012) revealed that AuNPs with various shapes, including quasi-spheres, triangles, and pentagonals, showed a lower catalytic activity for the reduction of $p$-nitroaniline to $p$ phenylenediamine than that of the uniform spherical nanoparticles. Thus, it is significant to accurately control the size and shape of biosynthesized AuNPs in order to improve their catalytic activities. Nevertheless, the present study demonstrated the potential application of biogenetic AuNPs in catalysis.

In conclusion, a low-cost and environment-friendly process for AuNP synthesis was developed using the cells and extracts of a novel fungus Mariannaea sp. HJ. Various reaction conditions, including initial gold ion concentration and $\mathrm{pH}$, could affect the shape and size of AuNPs, and the as-synthesized AuNPs were characterized by UV-vis spectroscopy, TEM, XRD, and FTIR analyses. The AuNP bioconjugates could be used as an efficient heterogeneous catalyst for the reduction of 4-NP. The present study has demonstrated the ability of AuNPs synthesized by the cells and extracts of Mariannaea sp. for the first time, which should provide insights into the green synthesis of metal nanoparticles.

Acknowledgements This work was supported by the National Natural Science Foundation of China (No. 51508068), the Program for New Century Excellent Talents in University (No. NCET-13-0077), the Fundamental Research Funds for the Central Universities (No. DUT14YQ107), and the Open Project of State Key Laboratory of Urban Water Resource and Environment, Harbin Institute of Technology (No. ESK201529).

\section{References}

Ahmad T, Wani IA, Manzoor N, Ahmed J, Asiri AM (2013) Biosynthesis, structural characterization and antimicrobial activity 
of gold and silver nanoparticles. Colloids Surf B Biointerfaces 107: 227-234

Aromal SA, Philip D (2012) Green synthesis of gold nanoparticles using Trigonella foenum-graecum and its size-dependent catalytic activity. Spectrochim Acta A Mol Biomol Spectrosc 97:1-5

Barabadi H, Honary S, Mohammadi MA, Ahmadpour E, Rahimi MT, Alizadeh A, Naghibi F, Saravanan M (2017) Green chemical synthesis of gold nanoparticles by using Penicillium aculeatum and their scolicidal activity against hydatid cyst protoscolices of Echinococcus granulosus. Environ Sci Pollut Res 2017:5800-5810

Bogireddy NKR, Anand KKH, Mandal BK (2015) Gold nanoparticlessynthesis by Sterculia acuminata extract and its catalytic efficiency in alleviating different organic dyes. J Mol Liq 211:868-875

Bradford MM (1976) A rapid and sensitive method for the quantitation of microgram quantities of protein utilizing the principle of protein-dye binding. Anal Biochem 72:248-254

Cai F, Li J, Sun JS, Ji YL (2011) Biosynthesis of gold nanoparticles by biosorption using Magnetospirillum gryphiswaldense MSR-1. Chem Eng J 175:70-75

Cai L, Kurniawati E, Hyde KD (2010) Morphological and molecular characterization of Mariannaea aquaticola sp. nov. collected from freshwater habitats. Mycol Prog 9:337-343

Castro ME, Cottet L, Castillo A (2014) Biosynthesis of gold nanoparticles by extracellular molecules produced by the phytopathogenic fungus Botrytis cinerea. Mater Lett 115:42-44

Daniel MC, Astruc D (2004) Gold nanoparticles: assembly, supramolecular chemistry, quantum-size-related properties, and applications toward biology, catalysis, and nanotechnology. Chem Rev 104:293346

Das SK, Dickinson C, Lafir F, Brougham DF, Marsili E (2012) Synthesis, characterization and catalytic activity of gold nanoparticles biosynthesized with Rhizopus oryzae protein extract. Green Chem 14:1322-1334

Edison TJI, Sethuraman MG (2012) Instant green synthesis of silver nanoparticles using Terminalia chebula fruit extract and evaluation of their catalytic activity on reduction of methylene blue. Process Biochem 47:1351-1357

Eustis S, El-Sayed MA (2006) Why gold nanoparticles are more precious than pretty gold: noble metal surface plasmon resonance and its enhancement of the radiative and nonradiative properties of nanocrystals of different shapes. Chem Soc Rev 35:209-217

Fukuda T, Sudoh Y, Tsuchiya Y, Okuda T, Fujimori F, Igarashi Y (2011) Marianins A and B, prenylated phenylpropanoids from Mariannaea camptospora. J Nat Prod 74:1327-1330

Gangula A, Podila R, Ramakrishna M, Karanam L, Janardhana C, Rao A (2011) Catalytic reduction of 4-nitrophenol using biogenic gold and silver nanoparticles derived from Breynia rhamnoides. Langmuir $27: 15268-15274$

Goi A, Trapido M (2002) Hydrogen peroxide photolysis, Fenton reagent and photo-Fenton for the degradation of nitrophenols: a comparative study. Chemosphere 46:913-922

Gu S, Wunder S, Lu Y, Ballauf M (2014) Kinetic analysis of the catalytic reduction of 4-nitrophenol by metallic nanoparticles. J Phys Chem C 118:18618-18625

Huang XQ, Chen X, Chen QC, Yu QQ, Sun DD, Liu J (2016) Investigation of functional selenium nanoparticles as potent antimicrobial agents against superbugs. Acta Biomater 30:397-407

Jana NR, Gearheart L, Murphy CJ (2001) Seeding growth for size control of 5-40 nm diameter gold nanoparticles. Langmuir 17:6782-6786

Kitching M, Ramani M, Marsili E (2015) Fungal biosynthesis of gold nanoparticles: mechanism and scale up. Microb Biotechnol 8:904917

Kumar SA, Peter YA, Nadeau JL (2008) Facile biosynthesis, separation and conjugation of gold nanoparticles to doxorubicin. Nanotechnology 19:495101
Kundu S, Lau S, Liang H (2009a) Shape-controlled catalysis by cetyltrimethylammonium bromide terminated gold nanospheres, nanorods, and nanoprisms. J Phys Chem C 113:5150-5156

Kundu S, Wang K, Liang H (2009b) Size-selective synthesis and catalytic application of polyelectrolyte encapsulated gold nanoparticles using microwave irradiation. J Phys Chem C 113:5157-5163

Lallawmawma H, Sathishkumar G, Sarathbabu S, Ghatak S, Sivaramakrishnan S, Gurusubramanian G, Kumar NS (2015) Synthesis of silver and gold nanoparticles using Jasminum nervosum leaf extract and its larvicidal activity against filarial and arboviral vector Culex quinquefasciatus Say (Diptera: Culicidae). Environ Sci Pollut Res 22:17753-17768

Lin LQ, Wu WW, Huang JL, Sun DH, Waithera NM, Zhou Y, Wang HT, Li QB (2013) Catalytic gold nanoparticles immobilized on yeast: from biosorption to bioreduction. Chem Eng J 225:857-864

Mandal D, Bolander ME, Mukhopadhyay D, Sarkar G, Mukherje P (2006) The use of microorganisms for the formation of metal nanoparticles and their application. Appl Microbiol Biotechnol 69:485492

Manivasagan P, Alam MS, Kang KH, Kwak M, Kim SK (2015) Extracellular synthesis of gold bionanoparticles by Nocardiopsis sp. and evaluation of its antimicrobial, antioxidant and cytotoxic activities. Bioprocess Biosyst Eng 38:1167-1177

Mishra A, Kumari M, Pandey S, Chaudhry V, Gupta KC, Nautiyal CS (2014) Biocatalytic and antimicrobial activities of gold nanoparticles synthesized by Trichoderma sp. Bioresour Technol 166:235242

Mishra A, Tripathy SK, Wahab R, Jeong SH, Hwang I, Yang YB, Kim YS, Shin HS, Yun SI (2011) Microbial synthesis of gold nanoparticles using the fungus Penicillium brevicompactum and their cytotoxic effects against mouse mayo blast cancer $\mathrm{C}_{2} \mathrm{C}_{12}$ cells. Appl Microbiol Biotechnol 92:617-630

Mishra P, Ray S, Sinha S, Das B, Khan MI, Behera SK, Yun SI, Tripathy SK, Mishra A (2016) Facile bio-synthesis of gold nanoparticles by using extract of Hibiscus sabdariffa and evaluation of its cytotoxicity against U87 glioblastoma cells under hyperglycemic condition. Biochem Eng J 105:264-272

Mukherjee P, Ahmad A, Mandal D, Senapati S, Sainkar SR, Khan MI, Ramani R, Parischa R, Ajayakumar PV, Alam M, Sastry M, Kumar $\mathrm{R}$ (2001) Bioreduction of $\mathrm{AuCl}_{4}{ }^{-}$ions by the fungus, Verticillium sp. and surface trapping of the gold nanoparticles formed. Angew Chem Int Ed 40:3585-3588

Narayanan KB, Sakthivel N (2010) Biological synthesis of metal nanoparticles by microbes. Adv Colloid Interf Sci 156:1-13

Narayanan KB, Sakthivel N (2011) Synthesis and characterization of nano-gold composite using Cylindrocladium floridanum and its heterogeneous catalysis in the degradation of 4-nitrophenol. J Hazard Mater 189:519-525

Okuda T, Yamamoto K (2000) Materials for the fungus flora of Japan (56) Mariannaea camptospora and M. elegans var. punicea from Japan. Mycoscience 41:411-414

Pereira L, Mehboob F, Stams AJM, Mota MM, Rijnaarts HHM, Alves MM (2015) Metallic nanoparticles: microbial synthesis and unique properties for biotechnological applications, bioavailability and biotransformation. Crit Rev Biotechnol 35:114-128

Pimprikar PS, Joshi SS, Kumar AR, Zinjarde SS, Kulkarni SK (2009) Influence of biomass and gold salt concentration on nanoparticle synthesis by the tropical marine yeast Yarrowia lipolytica NCIM 3589. Colloids Surf B Biointerfaces 74:309-316

Reddy V, Torati RS, Oh S, Kim C (2012) Biosynthesis of gold nanoparticles assisted by Sapindus mukorossi gaertn. Fruit pericarp and their catalytic application for the reduction of $p$-nitroaniline. Ind Eng Chem Res 52:556-564

Schröfel A, Kratošová G, Šafařík I, Šafaříková M, Raška I, Shor LM (2014) Applications of biosynthesized metallic nanoparticles - a review. Acta Biomater 10:4023-4042 
Shedbalkar U, Singh R, Wadhwani S, Gaidhani S, Chopade BA (2014) Microbial synthesis of gold nanoparticles: current status and future prospects. Adv Colloid Interf Sci 209:40-48

Shi C, Zhu N, Cao Y, Wu P (2015) Biosynthesis of gold nanoparticles assisted by the intracellular protein extract of Pycnoporus sanguineus and its catalysis in degradation of 4-nitroaniline. Nanoscale Res Lett 10:1-8

Sneha K, Sathishkumar M, Kim S, Yun YS (2010) Counter ions and temperature incorporated tailoring of biogenic gold nanoparticles. Process Biochem 45:1450-1458

Srivastava SK, Yamada R, Ogino C, Kondo A (2013) Biogenic synthesis and characterization of gold nanoparticles by Escherichia coli K12 and its heterogeneous catalysis in degradation of 4-nitrophenol. Nanoscale Res Lett 8:1

Tang L, Hyun MW, Yun YH, Suh DY, Kim SH, Sung GH, Choi HK (2012) Mariannaea samuelsii isolated from a bark beetle-infested elm tree in Korea. Mycobiology 40:94-99
Tripathi RM, Gupta RK, Singh P, Bhadwal AS, Shrivastav A, Kumar N, Shrivastav BR (2014) Ultra-sensitive detection of mercury(II) ions in water sample using gold nanoparticles synthesized by Trichoderma harzianum and their mechanistic approach. Sens Actuator B Chem 204:637-646

Xie JP, Lee JY, Wang DIC, Ting YP (2007) High-yield synthesis of complex gold nanostructures in a fungal system. J Phys Chem C 111:16858-16865

Zeng ZQ, Zhuang WY (2014) A new holomorphic species of Mariannaea and epitypification of M. samuelsii. Mycol Prog 13:980

Zhang XW, Qu YY, Shen WL, Wang JW, Li HJ, Zhang ZJ, Li SZ, Zhou JT (2016) Biogenic synthesis of gold nanoparticles by yeast Magnusiomyces ingens LH-F1 for catalytic reduction of nitrophenols. Colloids Surf A Physicochem Eng Asp 497:280-285

Zhao PX, Feng XW, Huang DS, Yang GY, Astruc D (2015) Basic concepts and recent advances in nitrophenol reduction by gold-and other transition metal nanoparticles. Coord Chem Rev 287:114-136 